\title{
Prognosis of patients with pulmonary embolism after rehabilitation
}

This article was published in the following Dove Press journal: Vascular Health and Risk Management

\author{
Mroawan Amoury' \\ Frank Noack ${ }^{1,2}$ \\ Kathleen Kleeberg ${ }^{3}$ \\ Dietrich Stoevesandt ${ }^{4}$ \\ Burghart Lehnigk ${ }^{5}$ \\ Steffi Bethge ${ }^{5}$ \\ Viktoria Heinze ${ }^{5}$ \\ Axel Schlitt ${ }^{3,5}$
}

'Department of Emergency Medicine, University Clinic Halle-Saale, Halle, Germany; ${ }^{2}$ Department of Medicine I, University Clinic Halle-Saale, Halle, Germany; ${ }^{3}$ Medical Faculty, Martin Luther-University Halle-Wittenberg, Halle, Germany; ${ }^{4}$ Department of Diagnostic Radiology, University Clinic Halle-Saale, Halle, Germany; ${ }^{5}$ Department of Cardiology and Pulmology, Paracelsus-Harz Clinic Bad Suderode, Quedlinburg, Germany
Correspondence: Axel Schlitt Paracelsus-Harz Clinic Bad Suderode Clinic, 06485 Quedlinburg, Germany Tel +493948599900

$\mathrm{Fax}+493948599812$

Email axel.schlitt@paracelsus-kliniken.de
Introduction: Pulmonary embolism (PE) is a life-threatening disease; in Germany, therefore, rehabilitation after $\mathrm{PE}$ is recommended in patients with intermediate- and high-risk PE. However, no prospective data on PE after inpatient rehabilitation have been published so far.

Patients and methods: For this monocentric study, 70 patients with PE were prospectively recruited between November 2013 and November 2014 after giving written informed consent. This study was approved by the ethics committee of the Medical Association of Saxony-Anhalt. Inclusion criteria were as follows: age $\geq 18$ years and a stay at the Paracelsus-Harz Clinic in Bad Suderode, Germany, with the main indication of PE. During the hospital stay, history-relevant medical data and diagnostic findings were collected and documented. Furthermore, we recorded whether patients were rehospitalized or died during the treatment period in the rehabilitation clinic or during the 12-month follow-up.

Results: The mean age was $64.5 \pm 13.0$ years, the mean body mass index (BMI) was $30.4 \pm$ $6.0 \mathrm{~kg} / \mathrm{m}^{2}$, and $54.3 \%$ were women. During rehabilitation, two patients $(3.9 \%)$ were transferred to a primary care hospital; no patient died. However, four patients died $(5.7 \%)$ in the 12 -month follow-up period. A total of 20 patients were hospitalized in the 12-month follow-up period (hospitalization rate during the 12-month follow-up period: $28.6 \%$ ). Of these 20 patients, one patient was rehospitalized with a newly diagnosed PE (1.4\%) and two patients were rehospitalized for bleeding events (2.8\%).

Conclusion: PE is a life-threatening disease, and therefore it seems reasonable to recommend rehabilitation at least in patients with an intermediate- or high-risk PE. In this study, death and other serious event rates were low during the in-hospital rehabilitation and in the 12-month follow-up period, which underlined the safety and importance of a standardized rehabilitation program after survived PE.

Keywords: pulmonary embolism, rehabilitation, prognosis

\section{Introduction}

Venous thromboembolism (VTE), including deep vein thrombosis (DVT) and pulmonary embolism (PE), is the third most frequent cardiovascular disease, and PE is a major cause of mortality, morbidity, and hospitalization in Europe. Fatal events occurred mostly as a result of sudden PE and $\sim 60 \%$ resulted from undiagnosed PE. Age is an important risk factor for developing a VTE, and older patients are at increased risk of fatal outcome after PE. ${ }^{1}$

If $\mathrm{PE}$ is correctly diagnosed, immediate anticoagulation and compression therapy of the limbs are indicated in the cases with DVT, where it is already present. Then, mobilization is indicated in patients with VTE. ${ }^{2}$ Early walking exercise is safe in patients 
with DVT and may help to reduce acute symptoms. Exercise training prevents or improves post-thrombotic syndrome. ${ }^{3}$ In low-risk VTE patients, early hospital discharge or outpatient treatment is recommended. ${ }^{1}$

Patients with an intermediate- or high-risk PE benefit from intensive therapy, including initial in-hospital treatment and a rehabilitation program after their hospital stay. Rehabilitation after PE with intermediate or high risk is recommended in Germany to improve dyspnea and functional capacity so as to reintegrate patients into daily life. ${ }^{3}$

However, data on rehabilitation after PE are limited. In a small study from the US, 19 of 239 patients who had suffered PE or DVT were prospectively randomized either to a 3-month outpatient sports program $(n=9)$ or to a control group $(n=10)$. During the 3 -month study period, no serious events were reported. Participants in the intervention group showed a significant decrease in body mass index (BMI) as well as a significant increase in physical activity and the maximum oxygen consumption when compared to the control group. ${ }^{4}$

Our group recently published a retrospective study on 422 patients with PE, who were treated in the ParacelsusHarz Clinic from 2006 to 2014. The rehabilitation program, consisting of a wide range of therapeutic interventions such as bicycle training and aquatic therapy/swimming, was safe and effective, because during the rehabilitation program no fatal events were retrospectively found and only four patients $(0.9 \%)$ had to be transferred to a primary care hospital for non-PE-associated reasons. ${ }^{5}$

\section{Patients and methods}

For the current study, 70 patients with PE were included between November 2013 and November 2014 in the Paracelsus-Harz Clinic, Quedlinburg, Germany. Inclusion criteria were as follows: admission to the Paracelsus-Harz Clinic for inpatient rehabilitation with a main indication of $\mathrm{PE}$ and an age of $\geq 18$ years. The patients were included after giving written informed consent. Patients were excluded from the study if they could not or did not wish to give written informed consent. The study was approved by the ethics committee of the Medical Association of Saxony-Anhalt.

PE was previously diagnosed in all patients by computed tomography (CT) angiography. DVT was additionally diagnosed in 30 patients (43\%).

Inpatient rehabilitation for patients with $\mathrm{PE}$ is adapted to the recommendations of the German Federal Pension Insurance (Deutsche Rentenversicherung Bund) for rehabilitation. Diagnostic procedures such as cycle ergometry (with blood gas analysis), echocardiography, and electrocardiogram (ECG) were included. For patients who were not able to perform cycle ergometry, a 6-minute walk test was conducted. Depending on physical fitness, severity of primary disease, comorbidities, and other confounders, a sports and rehabilitation program was set up. Patients in good clinical condition participated every day (except Sunday) in heart rate-monitored 30-minute cycle ergometry training. Moreover, these patients participated in Nordic walking, medical training therapy, intensive gymnastics/exercise, and pulmonological functional exercise and aquatic therapy.

Patients who were less physically fit participated in group exercises, chair exercises, walking exercises, and personal training sessions.

All patients, irrespective of their physical fitness, received respiratory training and attended seminars and lectures as part of the 3-week rehabilitation program.

In addition, psychosocial support was offered to all patients (social worker and/or psychologists).

During inpatient rehabilitation, the data relevant to the study such as medical history, drug treatment, results of ECG, echocardiography (according to the standard procedures of the clinic), and events such as need for hospitalization during rehabilitation were recorded and entered into a database (Microsoft Excel ${ }^{\circledR}$, Microsoft Excel 2016, Microsoft Corporation, Redmond, WA, USA).

For acquiring follow-up data, a standardized questionnaire was sent out at 3 and 12 months after inpatient rehabilitation at the Paracelsus-Harz Clinic, which included questions concerning adverse events such as hospital admission, bleeding complications, and thromboembolic events. If the patients did not send back the questionnaires, a telephone interview was conducted with the patient or his/her relatives, or the patient's physician was contacted. If this information could not be obtained from these persons, civil registration offices were contacted, and information was requested about current address or date of death.

\section{Statistical analyses}

Continuous variables were described as mean and SD and skewed variables as median and $25 \%$ and $75 \%$ quartiles. Categorical variables were documented as a percentage. Analyses were carried out with SPSS software (version 24; IBM Corporation, Armonk, NY, USA).

\section{Results}

A total of 70 patients were included. The mean age was 64.6 \pm 13.0 years, $54.3 \%$ were women, and the mean BMI was 
$30.2 \pm 5.8 \mathrm{~kg} / \mathrm{m}^{2}$. The length of stay at the rehabilitation clinic was $23.2 \pm 4.0$ days (Table 1). Heart rate at rest was $74.5 \pm$ $12.5 \mathrm{bpm}$ at admission, mean systolic blood pressure (132.8 $\pm 19.0 \mathrm{mmHg}$ ) and mean diastolic blood pressure (80.3 \pm $10.9 \mathrm{mmHg}$ ) were in the normal range and did not change during the 12-month study period (Table 2).

Other comorbidities, such as drug therapy, echocardiographic findings, and laboratory data are presented in Tables 1-5.

Most of the patients participated in therapeutic interventions such as bicycle training with monitored heart rate $(89.9 \%)$, medical training therapy $(84.1 \%)$, swimming $(87.0 \%)$, and others (Table 4$)$.

\section{Serious adverse events}

No patient died during rehabilitation. Two patients had to be transferred to a primary care hospital for non-PE-

Table I Patient characteristics

\begin{tabular}{ll}
\hline Variables & All patients (N = 70) \\
\hline Age (years) & $64.6 \pm 13.0$ \\
Women (\%) & 54.3 \\
Length of inpatient rehabilitation & $23.2 \pm 4.0$ \\
Patient history & \\
Active smoking (\%) & 7.1 \\
Hypertension (\%) & 68.6 \\
Coronary heart disease (\%) & 10.0 \\
Atrial fibrillation (\%) & 5.7 \\
Diabetes (\%) & 20.0 \\
Renal insufficiency (\%) & 15.7 \\
DVT (\%) & 42.8 \\
Echocardiographic data & \\
TAPSE (mm) & $23.4 \pm 4.3$ \\
Pulmonary artery pressure (mmHg) & $31.3 \pm 10.7$ \\
Left ventricular ejection fraction (\%) & $62.8 \pm 5.4$ \\
E/A & $1.0 \pm 0.3$ \\
E/E' & $12.0 \pm 4.2$ \\
Left atrial diameter (mm) & $38.7 \pm 5.3$ \\
Right ventricle dilated (\%) & 22.4 \\
Right atrium dilated (\%) & 28.4 \\
Tricuspid regurgitation (\%) & 53.7 \\
Diastolic dysfunction (\%) & 40.0 \\
\hline Not Congs &
\end{tabular}

Note: Continuous variables are reported as mean \pm SD and categorical variables as percentage.

Abbreviations: DVT, deep vein thrombosis; TAPSE, tricuspid annular systolic movement. associated reasons during the 3 -week rehabilitation period (2.8\%; Figure 1$)$. One patient suffered from a diverticulitis which was surgically treated. Another patient developed acute renal failure. Both patients returned to the rehabilitation clinic. No bleeding events occurred during in patient rehabilitation.

Four patients died during the 12-month follow-up (5.7\%; Figure 1). A total of 20 patients were admitted to the hospital during the 12-month follow-up (28.6\%; Figure 1). The most common reasons were orthopedic problems. Bleeding requiring hospitalization developed in two patients: one case with

Table 3 Laboratory parameters

\begin{tabular}{ll}
\hline Variables & All patients $(\mathbf{N}=\mathbf{7 0})$ \\
\hline Creatinine $(\mu \mathrm{mol} / \mathrm{L})$ & $85.7 \pm 32.1$ \\
GFR $(\mathrm{mL} / \mathrm{min})$ & $80.2 \pm 23.9$ \\
CRP $(\mathrm{mg} / \mathrm{L})$ & $2.9(5.9 / 7.4)$ \\
Leukocytes $(\mathrm{gpt} / \mathrm{L})$ & $6.6 \pm 1.3$ \\
Hemoglobin $(\mathrm{mmol} / \mathrm{L})$ & $8.3 \pm 0.9$ \\
Glucose $(\mathrm{mmol} / \mathrm{L})$ & $5.3 \pm 1.0$ \\
Total cholesterol $(\mathrm{mmol} / \mathrm{L})$ & $5.6 \pm 1.1$ \\
LDL cholesterol $(\mathrm{mmol} / \mathrm{L})$ & $3.7 \pm 1.0$ \\
\hline
\end{tabular}

Note: Continuous variables are reported as mean \pm SD; skewed variables are reported as median (interquartile range 25/75).

Abbreviations: CRP, C-reactive protein; GFR, glomerular filtration rate; LDL, low-density lipoprotein.

Table 4 Therapeutic interventions

\begin{tabular}{ll}
\hline Variables & $\begin{array}{l}\text { All patients } \\
(\mathbf{N}=\mathbf{7 0})\end{array}$ \\
\hline Bicycle training with monitored heart rate (\%) & 89.9 \\
Medical training therapy (\%) & 84.1 \\
Group exercising (\%) & 78.3 \\
Chair exercises (\%) & 46.4 \\
Group gymnastics (\%) & 17.4 \\
Group aquatic therapy (\%) & 4.3 \\
Pulmonological functional exercise as aquatic & 76.8 \\
therapy (\%) & \\
Walking exercise (\%) & 15.9 \\
Respiratory therapy/training (\%) & 95.7 \\
Nordic walking (\%) & 62.3 \\
Swimming (\%) & 87.0 \\
\hline
\end{tabular}

Table 2 Vital parameters during the study period

\begin{tabular}{|c|c|c|c|c|}
\hline Variables & Admission & Discharge & 3-month follow-up & I 2-month follow-up \\
\hline BMI $\left(\mathrm{kg} / \mathrm{m}^{2}\right)$ & $30.2 \pm 5.8$ & $30.2 \pm 5.8$ & $29.3 \pm 4.8$ & $29.3 \pm 4.7$ \\
\hline Weight (kg) & $87.5 \pm 17.4$ & $86.8 \pm 16.7$ & $86.5 \pm 16.8$ & $85.1 \pm 13.5$ \\
\hline Systolic blood pressure (mmHg) & $132.8 \pm 19.0$ & $130.4 \pm 15.9$ & $129.1 \pm 15.3$ & $127.8 \pm 13.5$ \\
\hline Diastolic blood pressure $(\mathrm{mmHg})$ & $80.3 \pm 10.9$ & $77.9 \pm 9.9$ & $76.5 \pm 9.4$ & $77.1 \pm 9.6$ \\
\hline Heart rate (bpm) & $74.5 \pm 12.5$ & $75.8 \pm 13.2$ & $72.6 \pm 12.0$ & $73.3 \pm 11.0$ \\
\hline
\end{tabular}

Abbreviation: BMI, body mass index. 
Table 5 Drug treatment during the study period

\begin{tabular}{lllll}
\hline Variables & Admission & Discharge & 3-month follow-up & I2-month follow-up \\
\hline Oral anticoagulants* (\%) & 100 & 100 & 100 & 67.3 \\
Aspirin (\%) & 11.4 & 2.9 & 5.4 & 7.7 \\
Beta-blockers (\%) & 37.1 & 47.1 & 50.0 & 44.2 \\
ACE inhibitors (\%) & 21.4 & 22.9 & 23.2 & 26.9 \\
ARBs (\%) & 32.9 & 32.9 & 33.9 & 36.5 \\
Calcium channel blockers (\%) & 24.3 & 30.0 & 26.8 & 23.1 \\
Statins (\%) & 18.6 & 30.0 & 23.2 & 23.1 \\
Insulin (\%) & 5.7 & 5.7 & 3.6 & 1.9 \\
Oral antidiabetics (\%) & 12.9 & 12.9 & 14.3 & 9.6 \\
Antidepressants (\%) & 14.3 & 14.3 & 8.9 & 11.5 \\
\hline
\end{tabular}

Note: *Rivaroxaban in all patients.

Abbreviations: ACE, angiotensin-converting-enzyme; ARB, angiotensin receptor blocker.

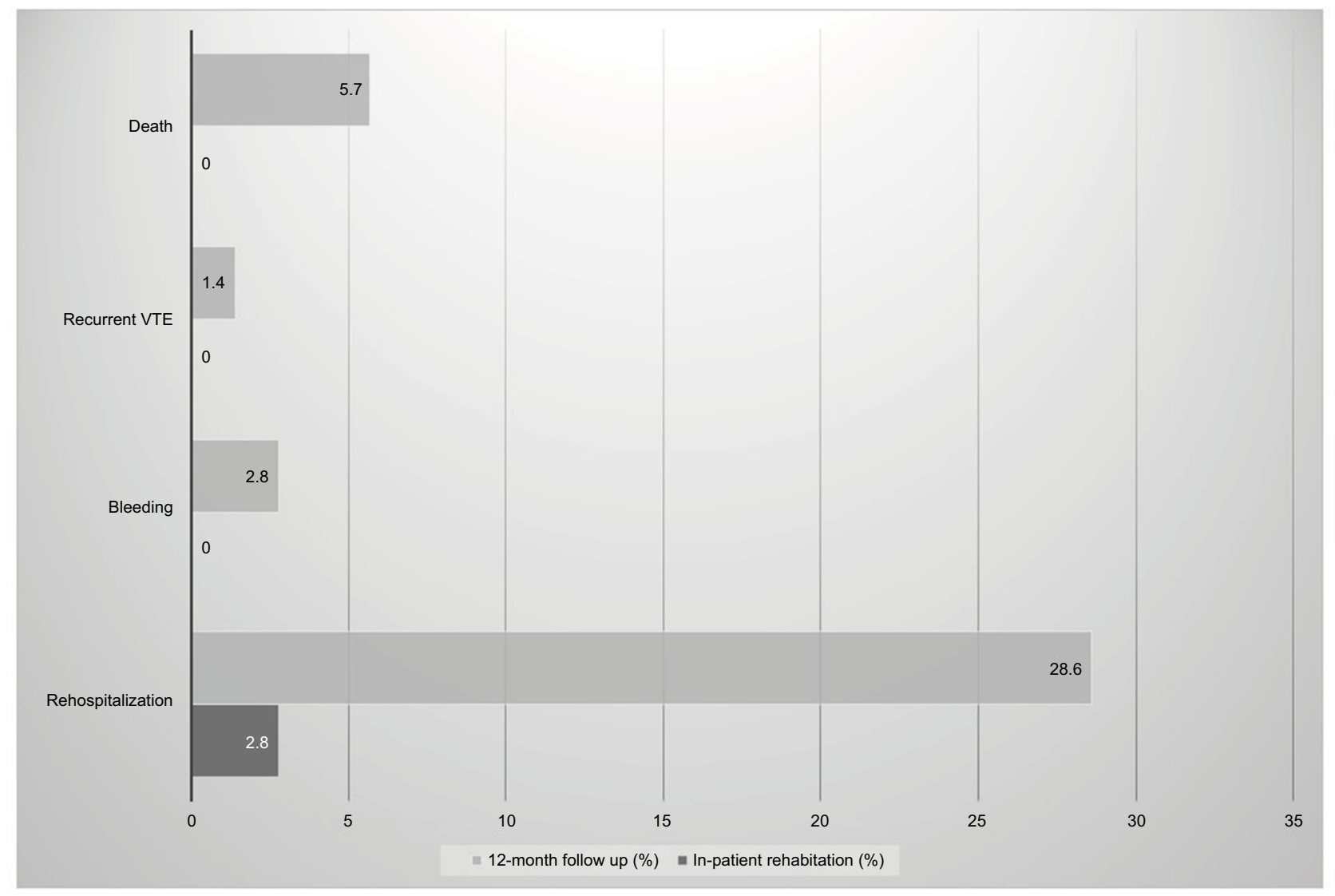

Figure I Serious adverse events during inpatient rehabilitation and I2-month follow-up periods. Abbreviation: VTE, venous thromboembolism.

epistaxis and one with gastrointestinal bleeding. Another patient was rehospitalized because of recurrent PE.

\section{Discussion}

The results of the current analyses, which represent the first prospective study of inpatient rehabilitation patients after $\mathrm{PE}$, show that 1) rehabilitation is safe as serious adverse events during the rehabilitation process, such as bleeding, rehospitalization for VTE reasons, or deaths, were not found;
2) rehospitalization for mainly non-PE reasons is common in 12 months after rehabilitation (28.6\%); and 3) prognosis of patients after rehabilitation is good as within the 12-month follow-up period only two patients had to be rehospitalized for bleeding complications and one patient for new PE and only four patients $(5.7 \%)$ died during the 1-year follow-up period.

Since prospective data on the effect of rehabilitation on the outcome of patients with $\mathrm{PE}$ are lacking, international guidelines do not recommend rehabilitation after PE. ${ }^{6,7}$ However, 
in Germany, rehabilitation is indicated in patients with serious cardiac and pulmonary diseases such as moderate-to-severe PE according to the medical requirements for rehabilitation issued by the federal pension funding agency (Sozialgesetzbuch IX = Social Code Book IX). Data supporting this recommendation came only from two single-center studies ${ }^{4,5}$ : safety and efficacy of an outpatient rehabilitation program were found in a small prospective study with 19 patients from the US ${ }^{4}$ and safety was shown in a retrospective study from a larger cohort of 422 patients from Germany. ${ }^{5}$ The prognosis of patients after PE after a rehabilitation program has not been investigated so far.

The current analysis shows 5.7\% 1-year mortality in patients after rehabilitation in our analysis which is markedly low in comparison to other data. In the PE-guideline from the European Society of Cardiology from 2014, "30-day allcause mortality rates between $9 \%$ and $11 \%$, and three-month mortality ranging between $8.6 \%$ and $17 \%$ " were summarized. ${ }^{1}$ Data from Denmark showed a 30-day mortality of $31.1 \%$ and a 1-year mortality of $\sim 44 \%$ in 54.066 patients after PE. ${ }^{8}$

However, in selected populations represented in clinical studies, total mortality was lower, for example, in the EINSTEIN-PE study comparing rivaroxaban with warfarin. In that study, $2.2 \%$ of patients died during the study period, ${ }^{9}$ and in the AMPLIFY study comparing apixaban with warfarin $\sim 1.7 \%$ died.${ }^{10}$ However, in these studies, the rate of recurrent VTE was comparable ( $2.0 \%$ in EINSTEIN-PE and $\sim 2.5 \%$ in AMPLIFY) to that in the current analysis (one patient with a recurrent PE representing $1.4 \%$ of the study population).

\section{Limitations}

The study is limited by the small number of patients and monocentric nature, which has the potential for underreporting of bleeding events as compared to other trials. Another limitation is the lack of a control group.

\section{Conclusion}

The current data underline the safety and importance of rehabilitation programs in patients with $\mathrm{PE}$.

\section{Acknowledgment}

This study was supported by an unrestricted grant from Actelion $^{\circledR}$ (Actelion Pharmaceuticals Deutschland GmbH, Freiburg im Breisgau, Germany).

\section{Disclosure}

The authors report no conflicts of interest in this work.

\section{References}

1. Konstantinides SV, Torbicki A, Agnelli G, et al; Task Force for the Diagnosis and Management of Acute Pulmonary Embolism of the European Society of Cardiology (ESC). 2014 ESC guidelines on the diagnosis and management of acute pulmonary embolism. Eur Heart J. 2014;35(43): 3069a-3069a.

2. Aissaoui N, Martins E, Mouly S, Weber S, Meune C. A meta-analysis of bed rest versus early ambulation in the management of pulmonary embolism, deep vein thrombosis, or both. Int J Cardiol. 2009;137(1): $37-41$.

3. Kahn SR, Shrier I, Kearon C. Physical activity in patients with deep venous thrombosis: a systematic review. Thromb Res. 2008;122(6):763-773.

4. Lakoski SG, Savage PD, Berkman AM, et al. The safety and efficacy of early-initiation exercise training after acute venous thromboembolism: a randomized clinical trial. J Thromb Haemost. 2015;13(7): 1238-1244.

5. Noack F, Schmidt B, Amoury M, et al. Feasibility and safety of rehabilitation after venous thromboembolism. Vasc Health Risk Manag. 2015;11:397-401.

6. Jaff MR, McMurtry MS, Archer SL, et al; American Heart Association Council on Cardiopulmonary, Critical Care, Perioperative and Resuscitation; American Heart Association Council on Peripheral Vascular Disease; American Heart Association Council on Arteriosclerosis, Thrombosis and Vascular Biology. Management of massive and submassive pulmonary embolism, iliofemoral deep vein thrombosis, and chronic thromboembolic pulmonary hypertension: a scientific statement from the American Heart Association. Circulation. 2011;123(16):1788-1830.

7. Kearon C, Akl EA, Comerota AJ, et al. Antithrombotic therapy for VTE disease: antithrombotic therapy and prevention of thrombosis, 9th ed: American College of Chest Physicians evidence-based clinical practice guidelines. Chest. 2012;141(suppl 2):e419S-e494S.

8. Søgaard KK, Schmidt M, Pedersen L, Horváth-Puhó E, Sørensen HAT. 30 -Year mortality after venous thromboembolism: a population-based cohort study. Circulation. 2014;130(10):829-836.

9. EINSTEIN-PE Investigators, Büller HR, Prins MH, et al. Oral rivaroxaban for the treatment of symptomatic pulmonary embolism. $N$ Engl J Med. 2012;366:1287-1297.

10. Agnelli G, Buller HR, Cohen A, et al; AMPLIFY Investigators. Oral apixaban for the treatment of acute venous thromboembolism. $N$ Engl J Med. 2013;369(9):799-808.
Vascular Health and Risk Management

\section{Publish your work in this journal}

Vascular Health and Risk Management is an international, peerreviewed journal of therapeutics and risk management, focusing on concise rapid reporting of clinical studies on the processes involved in the maintenance of vascular health; the monitoring, prevention and treatment of vascular disease and its sequelae; and the involvement of

\section{Dovepress}

metabolic disorders, particularly diabetes. This journal is indexed on PubMed Central and MedLine. The manuscript management system is completely online and includes a very quick and fair peer-review system, which is all easy to use. Visit http://www.dovepress.com/ testimonials.php to read real quotes from published authors. 